\title{
Kinetics of energy source utilization in Boophilus microplus (Canestrini, 1887) (Acari: Ixodidae) embryonic development
}

\author{
Eldo Campos ${ }^{a}$, Jorge Moraes ${ }^{a}$, Arnoldo R. Façanha ${ }^{a}$, Érica Moreira ${ }^{a}$, \\ Denise Valle ${ }^{\mathrm{b}, \mathrm{c}}$, Leonardo Abreu ${ }^{\mathrm{a}}$, Pedro P.A. Manso ${ }^{\mathrm{d}}$, \\ Aline Nascimento ${ }^{\mathrm{b}, \mathrm{c}}$, Marcelo Pelajo-Machado ${ }^{\mathrm{d}}$, Henrique Lenzi ${ }^{\mathrm{d}}$, \\ Aoi Masuda $^{\mathrm{e}}$, Itabajara da Silva Vaz Jr. ${ }^{\mathrm{e}}$, Carlos Logullo ${ }^{\mathrm{a}, *}$ \\ ${ }^{a}$ Laboratório de Química e Função de Proteínas e Peptídeos and Laboratório de Biologia Celular e Tecidual - CBB - UENF, \\ Avenida Alberto Lamego, 2000, Horto, Campos dos Goytacazes, RJ, CEP 28015-620, Brazil \\ ${ }^{\mathrm{b}}$ Laboratório de Fisiologia e Controle de Artrópodes Vetores, Departamento de Entomologia, Instituto Oswaldo Cruz, \\ FIOCRUZ, Avenida Brasil, 4365, Manguinhos, Rio de Janeiro, RJ, CEP 21045-900, Brazil \\ ${ }^{\mathrm{c}}$ Instituto de Biologia do Exército, IBEx, Laboratório de Entomologia, Rua Francisco Manuel, \\ 102 Benfica, Rio de Janeiro, RJ, CEP 20911-270, Brazil \\ d Departamento de Patologia, Instituto Oswaldo Cruz, FIOCRUZ, Avenida Brasil, 4365, \\ Manguinhos, Rio de Janeiro, RJ, CEP 21045-900, Brazil \\ ${ }^{\text {e }}$ Centro de Biotecnologia e Faculdade de Veterinária, UFRGS, Avenida Bento Gonçalves, 9500, \\ Prédio 43421, Porto Alegre, RS, C.P. 15005, CEP 91501-970, Brazil
}

Received 16 June 2005; received in revised form 23 January 2006; accepted 5 February 2006

\begin{abstract}
The present work evaluates the kinetics of utilization of the main potential energy sources throughout the embryonic developmental stages of Boophilus microplus. The embryonic development of this arthropod is completed in 21 days. Cellularization of the blastoderm occurs on the 6th day and is rapidly followed by germ band extension and segmentation, whose first signs are visible on the 7th day. Cellularization is typically a maternal-driven process, carried out by molecular determinants deposited in the oocyte during oogenesis. On the other hand, segmentation is of zygotic nature, being the consequence of the synthesis of various components by the growing embryo. The enhancement in total B. microplus RNA was observed after cellularization, corroborating the replacement of maternal-driven processes by embryonic zygotic expression. An abrupt increase in oxygen consumption was observed from cellularization until the 8th day of development. The reduction in dry weight at the same period and the susceptibility of oxygen consumption to $\mathrm{KCN}$ suggest that the respiration process is activated during early embryonic development. A marked decrease in total lipid content occurred between the 5th and 7th days of development, suggesting this is the main energy source for cellularization. A major reduction in carbohydrate content occurred later, between the 7th and 9th days, and it could be assigned to the morphological segmentation of the embryo. Although the total amount of proteins remains unchanged from oviposition to hatching, a 15\% reduction in vitellin (VT) content was observed
\end{abstract}

\footnotetext{
* Corresponding author. Tel.: +55 222726 1467; fax: +55 2227261520 .

E-mail address: logullo@uenf.br (C. Logullo).
} 
before cellularization, up to the 4 th day after egglaying. This observation was correlated to the synthesis of new proteins needed to support early embryo development. Additional $20 \%$ of VT was consumed thereafter, mainly at the end of embryogenesis, and in this case VT is probably used as energy source to the older embryo. Altogether, these data indicate different energy sources for maternal and zygotic driven processes.

(C) 2006 Elsevier B.V. All rights reserved.

Keywords: Egg; Energy metabolism; Boophilus; Embryogenesis; Yolk proteins

\section{Introduction}

Bovine cattle blood is the unique feeding source supporting development of the Ixodidae tick Boophilus microplus. This ectoparasite is also the vector of babesiosis and anaplasmosis, imposing serious economic losses to several countries (Guerrero et al., 2005). Larval, nymphal, and adult development of this tick takes place on a single bovine host, within a period of 2-4 weeks. The adult female, after completion of engorgement, drops off the host and initiates oviposition 3 days later. Hatching occurs around 21 days after egglaying and the resulting larvae can survive many months before finding a new host, where development proceeds up to adult stages (Corson et al., 2004).

This arthropod increases its body weight about 100 times after blood meal. As a consequence of digestion, a great amount of food is processed and used in yolk synthesis, wherewith the growing embryo meets energy and nutrition needs (Sonenshine, 1991). The main yolk protein, called Vitellin (VT), is a heme-protein in ticks and is responsible for the brown egg color (Boctor and Kamel, 1976; Rosell and Coons, 1991; James and Oliver, 1997; Logullo et al., 2002). Heme-proteins are involved in a wide variety of biological processes, including respiration, oxygen transport and oxygen metabolism (Ponka, 1997). Oxygen consumption is a major parameter characterizing respiratory metabolism, and has been widely used to study the influence of several environmental factors in arthropod development and physiology (Madhavan, 1975; Braune, 1976; Tonzetich et al., 1976; Petitpren and Knight, 1979).

As a rule, oviparous animals face embryogenesis in the absence of exogenous nutrients. In this case, maternal nutrients are packaged into the oocytes, stored mostly as yolk granules (Fagotto, 1990; Sappington and Raikhel, 1998). Maturation occurs during the preoviposition phase, characterized by a rapid increase in ovarian size (Cherry, 1973). It is at this phase that oocytes exhibit fast growth, accumulating RNAs, carbohydrates, lipids and proteins that will meet the regulatory and metabolic needs of the developing embryo (Chippendale, 1978). Lack of any required yolk component may restrain or even block embryo development inside the egg (Thompson and Russel, 1999). Previous studies performed with birds have focused on the importance of various egg components to the developing embryo, as well as on the mechanisms that transport nutrients from the yolk to their utilization sites in embryonic tissues (Speake et al., 1998).

Current literature provides ample data regarding the regulatory cascade of events that control development during arthropod embryogenesis. Nevertheless, little information is available concerning energy metabolism during embryonic development. Knowledge of this process could reveal potential targets to control arthropod disease vectors or agricultural pests. The B. microplus tick is an ectoparasite responsible for weight losses and skin damage in bovine cattle. Apart from this, the organism is a vector of several diseases.

Here we quantified the major classes of potential energy sources in the course of $B$. microplus embryogenesis. Oxygen consumption was also measured in order to follow the respiratory metabolism. These data were correlated to the different embryonic stages, whose morphology was evaluated by confocal microscopy. We suggest that distinct sources of energy are mobilized in the course of $B$. microplus embryogenesis, and that switches among different energy sources occur at specific development stages.

\section{Materials and methods}

\subsection{Ticks}

Ticks were obtained from a colony maintained at the Faculdade de Veterinária, Universidade Federal do 
Rio Grande do Sul, Brazil. B. microplus ticks from the Porto Alegre strain, free of Babesia spp., were reared on calves obtained from a tick-free area. Engorged adult females were kept in Petri dishes at $28{ }^{\circ} \mathrm{C}$ and $80 \%$ relative humidity upon completion of oviposition, which starts about 3 days after dropping off the calves. Eggs were collected on different days during embryogenesis and stored at $-20{ }^{\circ} \mathrm{C}$.

\subsection{Histological procedures}

B. microplus eggs underwent the protocol classically used to dechorionate Drosophila melanogaster embryos (Forbes and Ingham, 1993). Briefly, eggs were submerged in a $20 \%$ sodium hypochlorite bath for $2-4 \mathrm{~min}$. After rinsing in water, eggs were fixed in a biphasic 10:9:1 mixture of heptane: $4 \%$ paraformaldehyde in PBS: dimethyl sulfoxide (DMSO), for 20 min under mild agitation. The lower aqueous phase (containing the fixative plus DMSO) was then replaced with $100 \%$ methanol and the remaining biphasic mixture was vigorously shaken for $30 \mathrm{~s}$. Completely or partially dechorionated $B$. microplus eggs fell to the bottom of the tube and were collected, rinsed twice with $100 \%$ methanol and stored at $-20^{\circ} \mathrm{C}$. Prior to use, eggs were submitted to a serial rehydration with 70, 50 and $30 \%$ ethanol in PBS, followed by three washes in PBS. Incubation with Acridine Orange or Evans Blue (both at $0.01 \%$ in PBS) was performed for $20 \mathrm{~min}$ and enabled the visualization of nuclei and cell limits, respectively. Whole eggs were directly observed on a Zeiss LSM 410 laser scanning confocal microscope, using a $488 \mathrm{~nm}$ laser beam and a BP 510$525 \mathrm{~nm}$ filter for the visualization of acridine orange or, alternatively, a $543 \mathrm{~nm}$ laser beam and a LP $570 \mathrm{~nm}$ filter for Evans blue, respectively.

\subsection{Oxygen consumption}

The total oxygen consumed by embryonated eggs at different times after oviposition was assayed using a Clark-type electrode (YSI, mod. 5775, Yellow Springs, $\mathrm{OH})$. The calibration process was executed using $100 \%$ as complete air-saturated buffer at $28{ }^{\circ} \mathrm{C}$. Measurements were carried out in $3 \mathrm{~mL} 20 \mathrm{mM}$ PBS buffer (pH 7.4); 0.1 mM EDTA, and the rate of oxygen consumption was calculated in $\mu \mathrm{mol} \mathrm{O}_{2} / \mathrm{min} \mathrm{mg}$ egg. A solution containing $1 \mathrm{mM} \mathrm{KCN}$ was added to inhibit cytochrome oxidase. The same solution was used as negative control. For each day after oviposition evaluated, three assays were performed using $200 \mathrm{mg}$ of eggs.

\subsection{Determination of dry weight and water content}

Three samples of 300 eggs were used in each determination. After counting, groups of eggs at different days after oviposition were weighed on a Shimadzu balance AX200 and dried at $85^{\circ} \mathrm{C}$ until constant weight was attained. The water content was calculated as the difference in weight values before and after drying. Three samples were analyzed for each experimental point.

\subsection{RNA content}

RNA was extracted from $50 \mathrm{mg}$ of egg homogenates with Tri-reagent (Sigma, inc.) according to the manufacturer's instructions and precipitated with $0.5 \mathrm{~mL}$ isopropanol for $10 \mathrm{~min}$ at room temperature. Subsequently, the extracted RNA was washed with $1 \mathrm{~mL}$ $75 \%$ ethanol, vacuum-dried for $10 \mathrm{~min}$ and resuspended in $1 \mathrm{~mL}$ water. Absorbance was measured at 260 and $280 \mathrm{~nm}$, assuming that one absorbance unity at $A_{260}$ corresponds to $40 \mu \mathrm{g}$ RNA (Sambrook et al., 1989).

\subsection{Total protein content}

Five milligrams of eggs were homogenized in $1 \mathrm{~mL}$

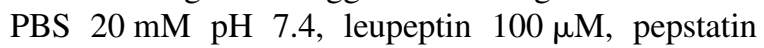
$100 \mathrm{nM}$ and benzamidine. $1 \mathrm{mM}$ and centrifuged at $11,000 \times g$ for $5 \mathrm{~min}$. Total protein content was quantified according to Bradford (1976) in $10 \mu \mathrm{L}$ aliquots, using bovine serum albumin as standard. Three samples were analyzed for each experimental point.

\subsection{Total sugar content}

Ten milligrams of eggs were homogenized in $1 \mathrm{~mL}$ PBS $20 \mathrm{mM} \mathrm{pH} 7.4$ and centrifuged at $11,000 \times g$ for $5 \mathrm{~min}$. Aliquots of $50 \mu \mathrm{L}$ were added to $20 \mu \mathrm{L} 80 \%$ phenol, $1 \mathrm{~mL} \mathrm{H}_{2} \mathrm{SO}_{4}$ and $350 \mu \mathrm{L}$ water, vortexed and then left at room temperature for $30 \mathrm{~min}$. Absorbance was read at $490 \mathrm{~nm}$ using a molar extinction coefficient of $6.22 \mathrm{M}^{-1}$ (Dubois et al., 1956), and 
total sugar content was calculated based on a glucose standard curve. Three samples were analyzed for each experimental point.

\subsection{Total lipid content}

Egg homogenate aliquots containing $10 \mathrm{mg}$ of protein each were extracted with chloroform-methanol-water (2:1:0.5; v/v) (Bligh and Dyer, 1959). The organic phase was dried under a $\mathrm{N}_{2}$ stream and weighed to determine lipid content. Three samples were analyzed for each experimental point.

\subsection{Vitellin quantification}

Determination of VT content was performed using an enzyme-linked immunosorbent assay (ELISA). Egg homogenates from the 1st to the 20th day of embryogenesis (90 ng protein) in PBS were spotted onto ELISA plates as $100 \mu \mathrm{L}$ aliquots and incubated overnight. Plates were blocked with 5\% (W/V) non-fat dry milk, $0.5 \%$ (V/V) Tween 20 in PBS, and incubated with anti-VT polyclonal antibody (Logullo et al.,
2002) diluted 1:5000 in PBS containing 5\% non-fat dry milk for $2 \mathrm{~h}$. Goat anti-rabbit IgG conjugated to Alkaline Phosphatase (Sigma, inc.) diluted to $1: 10,000(\mathrm{~V} / \mathrm{V})$ was used as secondary antibody. After 90 min incubation in $p$-nitrophenyl phosphate, which served as substrate, the amount of VT in each sample was determined using a Thermomax microplate reader (Molecular Devices, Sunnyvale CA). A standard curve was made using VT purified from eggs collected on the 1st day after oviposition.

\section{Results}

The present work correlates the mobilization kinetics of some components of B. microplus eggs with the morphological changes that take place during early embryogenesis.

\subsection{Morphology}

The early stages of $B$. microplus embryogenesis were visualized by confocal scanning microscopy
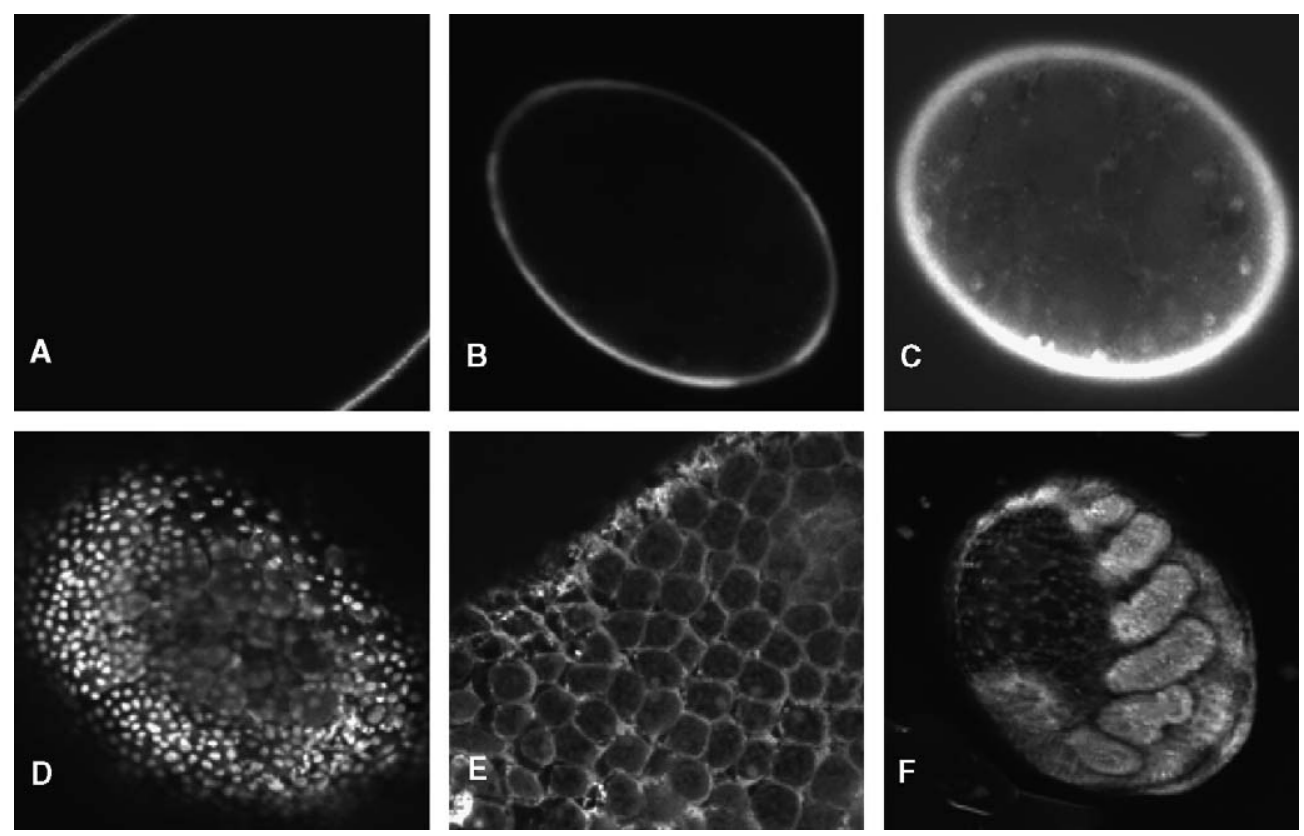

Fig. 1. Morphology of early B. microplus embryos. Permeabilized eggs of different days after oviposition were submitted to laser scanning confocal microscopy. (A) No labeling (only auto-fluorescence); (B-F) Acridine Orange labeling; (E) Evans blue labeling. (A, D, E) 6-day-old; (B) 1-day-old; (C) 4-day-old; (F) 7-day-old embryo. A black and white projection of a 3D reconstruction of a well-segmented embryo is shown in panel F. Note that only the chorion is auto-fluorescent (panel A). Acridin Orange and Evans blue labeling show nuclei and cell limits, respectively. 
(Fig. 1). It was first verified that, with exception of the chorion, embryos of this species are not autofluorescent (Fig. 1A), a characteristic that allowed labeling with exogenous markers. Visualization of nuclei labeled with Acridine Orange revealed almost no staining on the 1st day after oviposition (Fig. 1B). On the 4th day, nuclei had proliferated and attained the cortical cytoplasm, a pattern typical of syncitial blastoderm (Fig. 1C). A mitotic burst occurred between days four and six, as judged by the density of nuclei observed on the 6th day after oviposition (Fig. 1D). Evans Blue staining of 6-day-old embryos, but not of earlier ones, confirmed that cellularization had taken place (Fig. 1E), characterizing the cellular blastoderm stage. Afterwards, embryo development quickly progressed to the germ band extension phase: on the 7th day after egglaying, the embryo was clearly distinguished from the extra-embryonic membrane and segmentation was evident (Fig. 1F).

\subsection{Oxygen consumption}

No detectable oxygen consumption was verified on the 1st day after oviposition. From that point on, intense activation of the respiration process occurred until the 12th day of embryonic development. Oxygen consumption was completely blocked at all stages by addition of $1 \mathrm{mM} \mathrm{KCN}$ in the reaction medium (Fig. 2).

\subsection{Determination of dry weight and water content}

Both the B. microplus eggs' dry weight and the water content remained constant during early development, up to the 6th day after egglaying (Fig. 3). A decrease in dry weight was observed between the 7th and 9th days, when the total dry mass dropped from $15.7 \pm 1.3$ to $12.6 \pm 1.4 \mu \mathrm{g} / \mathrm{egg}$, corresponding to a loss of $18.4 \%$. At the same time, the water content increased from $24.3 \pm 1.3$ to $27.2 \pm 1.4 \mu \mathrm{g} / \mathrm{egg}$ of the total eggs' weight, corresponding to $11.2 \%$ (Fig. 3).

\subsection{Consumption of energetic sources during embryogenesis}

The total lipid content remained stable until the 5th day $(2.07 \pm 0.46 \mu \mathrm{g} / \mathrm{egg})$, dropping to approximately $1.1 \mu \mathrm{g} / \mathrm{egg}$ on the 7 th day, a value that was kept roughly

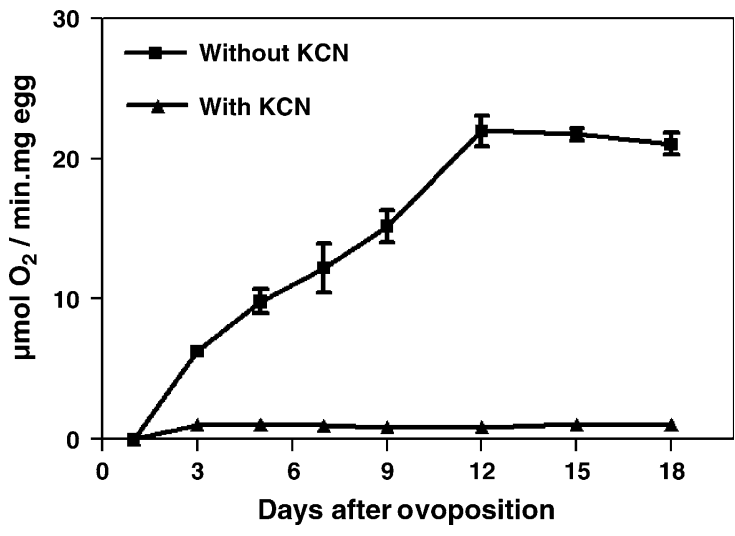

Fig. 2. Oxygen consumption. Oxygen consumption of B. microplus embryos was assayed using a Clark-type electrode calibrated to $100 \%$ with air-saturated buffer at $28{ }^{\circ} \mathrm{C}$. ( $\square$ ) Kinetics of oxygen consumption at different days after oviposition. ( $\boldsymbol{\Delta}$ ) effect of a $1 \mathrm{mM}$ KCN solution, inhibitor of cytochrome oxidase. Aliquots containing $200 \mathrm{mg}$ of eggs were assayed in all cases. Data shown are mean \pm S.E.M. $(n=3)$.

unchanged until hatching (Fig. 4A). Total sugars exhibited similar kinetics, although slightly delayed: values remained stable until the 7th day $(1.86 \pm$ $0.40 \mu \mathrm{g} / \mathrm{egg}$ ), dropped to $1.18 \mu \mathrm{g} / \mathrm{egg}$ on the 9th day (a 36.6\% decrease) and were kept constant until hatching (Fig. 4B). The sugar and the lipid kinetics accompanied the dry weight changes, shown in Fig. 3. The changes in total RNA amount during embryogenesis are shown in Fig. 4C. The total amount of RNA was almost constant during the first 3 days, rose quickly between the 6th and the 9th days after oviposition, and did not exhibit significant changes thereafter.

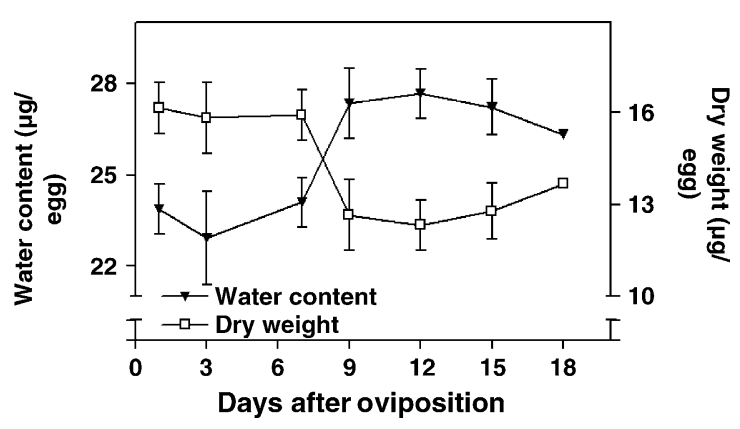

Fig. 3. Changes in dry weight and water content. The dry weight of eggs at different days after oviposition was determined with an analytical balance to the nearest $0.0001 \mathrm{~g}$. Each aliquot contained 300 eggs. The water content was calculated as the difference in weight values before and after drying. Data shown are mean \pm S.E.M. $(n=3)$. 

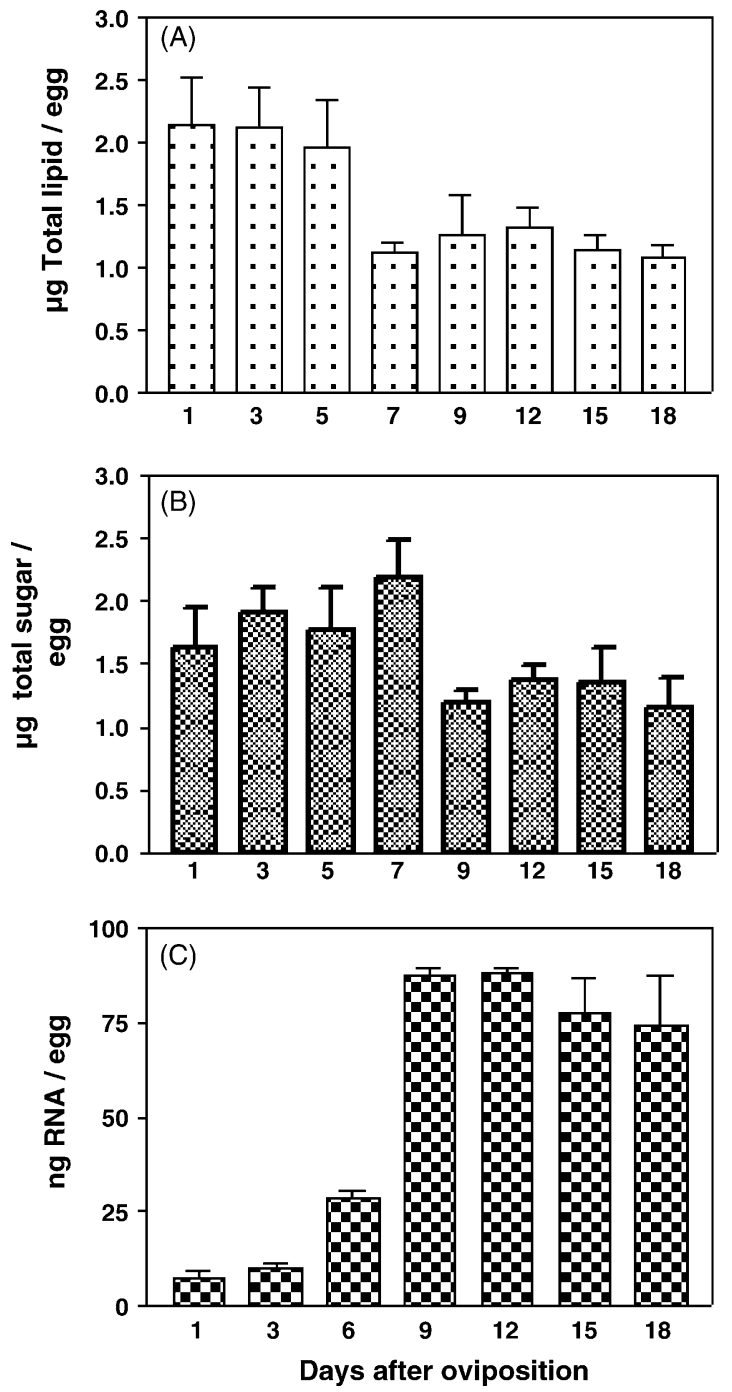

Fig. 4. Consumption of energetic sources. Major B. microplus egg storage components were quantified at different days after oviposition. (A) Lipid quantification, determined by gravimetric method (Bligh and Dyer, 1959); (B) total sugar concentration, measured using Dubois' method; (C) total RNA, extracted from egg $(50 \mathrm{mg}$ ) homogenate; absorbance was read at 260 and $280 \mathrm{~nm}$, using a molar extinction coefficient of $6.22 \mathrm{M}^{-1}$. Data shown are mean \pm S.E.M. $(n=3)$.

\subsection{Protein mobilization}

Vitellin (VT), the main yolk protein, represents $80 \%$ of total B. microplus egg protein content on the 1st day after oviposition. No significant changes in total protein content were observed throughout B. microplus

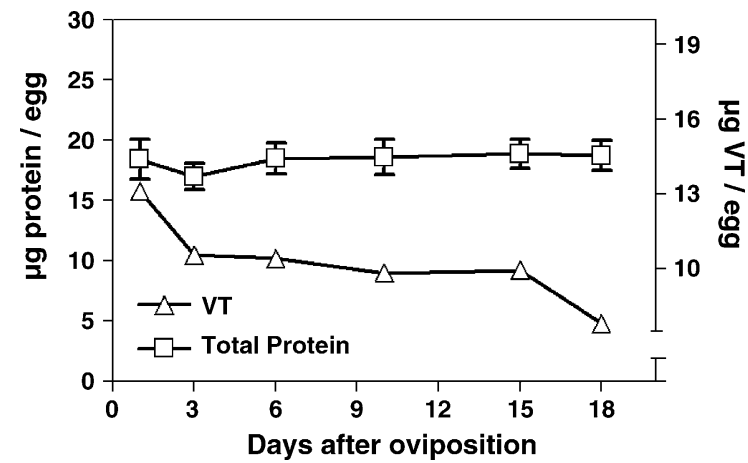

Fig. 5. Protein mobilization. Total protein concentration was measured, during B. microplus embryogenesis, using Bradford' method. The amount of VT in egg homogenates was determined using antiVT polyclonal antibody with the enzyme-linked imunosorbent assay (ELISA). Data shown are mean \pm S.E.M. $(n=3$ or 4$)$.

embryogenesis (Fig. 5). In contrast, around $15 \%$ of VT is mobilized during the initial 4 days of embryonic development while an additional $20 \%$ of VT is consumed until the 18th day after oviposition (Fig. 5).

\section{Discussion}

Development in invertebrates has been analyzed under different aspects, morphogenesis and cell cycle control being outstanding examples (Nusslein-Volhard and Roth, 1989; Bate and Arias, 1993; Edgar et al., 1994; Patel, 1994). Mobilization of yolk components, especially Vitellin, the major protein constituent of arthropod's eggs, has also been the subject of several reports (Takahashi et al., 1993; Abreu et al., 2004). However, there is a lack of information regarding the dynamics of energetic metabolism during embryogenesis.

The metabolic costs of embryonic development can be defined as the total amount of energy consumed by an embryo during its development, including the demands by growth or biosynthesis and by tissue maintenance (Thompson and Stewart, 1997). The present work evaluated the kinetics from the utilization of the main potential energy sources available during the embryonic development of the cattle tick, B. microplus. As information on tick embryo development was but scarcely available (Sonenshine, 1991), we first evaluated the morphology of embryos mainly on the early phases of their development. 
The B. microplus embryonic development is completed in 21 days when the specimens are reared at $28{ }^{\circ} \mathrm{C}$. Until the 5th day after oviposition, the $B$. microplus embryo is a syncitium. Cellularization of the blastoderm occurs on the 6th day, being followed by impressively quick movements: by the 7 th day a segmented germ band can already be distinguished (Fig. 1). Rapid early embryonic movements are typical of the model system D. melanogaster and have also been observed in mosquitoes (Bate and Arias, 1993; Monnerat et al., 2002).

Cellularization of $D$. melanogaster embryos is a synchronous process and a maternal-driven phenomenon, regulated exclusively by factors deposited in the oocyte during oogenesis. In this species, cellularization is a key event that definitively switches control of the embryonic development to the embryo itself: cells loose synchrony and the progression to later stages relies on zygotic transcription (Bate and Arias, 1993).

The quick developmental kinetics observed in early B. microplus embryos requires a readily available energetic support. In fact, an increase in oxygen consumption was noted until the 12th day after oviposition, a period that includes the cellularization and segmentation of B. microplus embryos. Oxygen consumption was completely inhibited by addition of $\mathrm{KCN}$, further confirming the activation of the respiration process (Fig. 2). To our knowledge, evaluations of oxygen consumption during the life cycle of arthropods are restricted to post-embryonic development stages (Guerra and Cochran, 1970; Petitpren and Knight, 1979; Gromysz-Kalkowska and Lechowski, 1992). Parallel to the abrupt rise in oxygen consumption at the beginning of development, a significant reduction of $B$. microplus eggs' dry weight is observed, corroborating an active respiration process. Moreover, this is accompanied by an increase in egg total water content, detectable between the 7th and the 9th days after oviposition (Fig. 3). Increase in water content is probably a consequence of the intense metabolic activity and respiration that take place inside the egg during this period (Figs. 2 and 3). It is noteworthy that a decrease in B. microplus eggs' dry weight occurs mainly after the tick embryo cellularization, when segmentation is rapidly achieved. The reduction in dry weight and the increase in oxygen consumption were also observed in the fish Solea senegalensis, but only in the latest embryonic stages (Parra et al., 1999).
Quantification of the major constituents of the egg in the course of B. microplus embryogenesis suggests that lipids and carbohydrates are the major energy sources, specifically during early embryo development. For both classes of molecules, amounts were observed to remain the same, except between the 5th and the 7th days for lipids and between the 7th and the 9 th days for carbohydrates. This kinetics suggests the utilization of lipids in the course of cellularization, a maternal-driven process (Bate and Arias, 1993). On the other hand, carbohydrates would be the major energy source for the quick segmentation of the embryo, of zygotic nature (Nusslein-Volhard and Roth, 1989; Bate and Arias, 1993).

Changes in nucleic acids content, particularly RNA, reflect the anabolic activities of the developing arthropod embryo and the degree of embryonic independence of the material of maternal origin. The increase in B. microplus total RNA content between the 6th and the 9th days after oviposition confirms an intense zygotic transcription activity after cellularization of the blastoderm, when development proceeds towards segmentation. These data suggest that maternal-driven processes are replaced by embryonic zygotic expression after cellularization of the blastoderm. A steady increase in total RNA content at the beginning of embryonic development has also been described for Tribolium confusum and for the tick Hyalomma dromedarii (Amnai-Devi et al., 1963; Kamel et al., 1982).

Proteins are the largest components of the yolk and VT is its major constituent. The total protein content in B. microplus eggs remains unchanged from oviposition to hatching (Fig. 5). This is in agreement with data from the tick H. dromedarii (Kamel et al., 1982). However, a significant decrease in B. microplus VT content during the first 4 days of embryogenesis was verified. An additional decrease in VT was observed between the 6th and the 18th days of development. The decrease in VT content without a parallel depletion of total proteins suggests that its final destination should be the synthesis of new proteins. This is expected to be the case, mainly with the VT depletion during the first 4 days, when VTderived amino acids are probably the source of newly synthesized proteins that will support blastoderm formation. Guanine is the product of amino acid catabolism in arachnids (Urich, 1990) and its quantification in B. microplus' eggs revealed an increase in the 
concentration of this metabolite after cellularization, on the 6th day (data not shown). Therefore, part of the VT that is consumed from that point on could provide the amino acids to be used as energy source to the growing embryo, at later development stages (Fig. 5).

It should be noted that only $40 \%$ of the VT deposited in B. microplus oocytes is utilized during embryogenesis (Logullo et al., 2002). It is essential for the newly hatched tick larvae to identify a new host in order to proceed to further development stages. Their survival depends upon the remaining nutritional supply brought from the egg and on the metabolic rate of energy consumption during the early stages of post-embryonic development (Sonenshine, 1991).

In conclusion, it is likely that the energetic metabolism of B. microplus embryos is a dynamic process which varies with the progression of morphological stages and with the control of the cell cycle during development. Early embryogenesis requires maternal regulatory factors, like specific RNAs, deposited in the oocyte during oogenesis. An intense translational activity is inferred from the depletion of the major yolk protein, VT, without concomitant decrease in the embryo total proteins. With cellularization of the blastoderm, on the 6th day, the embryo itself assumes the control of its development, through activation of zygotic expression. This fact is reflected in the increase of total RNA, starting on the 6th day after oviposition. The development progresses quickly to segmentation, whose first signs are already visible on the 7 th day after egglaying. An intense metabolism during embryo cellularization and segmentation is reflected both on the decrease in total egg's dry weight and on the increase of oxygen consumption at this period. A switch in energy source is also proposed to occur in parallel to the progression from maternal to zygotic control of development, since our data suggest lipids as the main energy source during cellularization, with carbohydrates accomplishing this role during embryo segmentation.

B. microplus is a one-host tick that causes major losses to bovine herds, especially in tropical regions, and major efforts have been made to develop immunoprophylatic tools against it. In this sense, knowledge of the processes involved in embryonic development may unravel additional targets that could be effective in the control of this ectoparasite.

\section{Acknowledgements}

We are grateful to Cristóvão Barros Pinheiro for his excellent technical assistance. The authors are indebted to Regina Aparedida Caldeira for a critical reading of the manuscript. This work was supported by grants from Fundação de Amparo à Pesquisa do Estado do Rio de Janeiro - FAPERJ, Conselho Nacional de Desenvolvimento Científico e Tecnológico - CNPq and Programa de Núcleos de Excelência - PRONEX.

\section{References}

Abreu, L., Valle, D., Manso, P.P.A., Façanha, A.R., Pelajo-Machado, M., Masuda, H., Masuda, A., Vaz Jr., I.S., Lenzi, H.L., Oliveira, P.L., Logullo, C., 2004. Proteolytic activity of Boophilus microplus yolk pro-cathepsin D (BYC) is coincident with cortical acidification during embryogenesis. Insect Biochem. Mol. Biol. 34, 443-449.

Amnai-Devi, A.L., Strivastava, U., Sarkar, N.K., 1963. Nucleic acid and protein metabolism in Tribolium confusum. Exp. Cell Res. 29, 443-450.

Bate, M., Arias, M., 1993. The Development of Drosophila melanogaster. Cold Spring Harbor Laboratory Press, New York.

Bligh, E.G., Dyer, W.J., 1959. A rapid method of total lipid extraction and purification. Can. J. Biochem. Physiol. 37, 911-917.

Boctor, F.N., Kamel, M.Y., 1976. Purification and characterization of two lipovitellins from eggs of the tick Dermacentor andersoni. Insect Biochem. 6, 223-240.

Bradford, M.M., 1976. A rapid and sensitive method for the quantification of microgram quantities of protein utilizing the principle of protein-dye binding. Anal. Biochem. 72, 248254.

Braune, H.J., 1976. Effects of temperature on the rates of oxygen consumption during morphogenesis and diapause in the egg stage of Leptopterna dolobrata. Oecologia (Berl.) 25, 7787.

Cherry, L.M., 1973. The accumulation and utilization of food reserves by adult female cattle tick, Boophilus microplus (canestrine). Aust. J. Zool. 21, 403-412.

Chippendale, G.M., 1978. Carbohydrates in reproduction and embryonic development. In: Biochemistry of Insects, Academic Press, New York, pp. 42-45.

Corson, M.S., Teel, P.D., Grant, W.E., 2004. Microclimate influence in a physiological model of cattle-fever tick (Boophilus spp.) population dynamics. Ecol. Modell. 180, 487-514.

Dubois, Gilles, K.A., Hamilton, J.K., Rebers, P.A., Smith, F., 1956. Calorimetric method for determination of sugar and related substances. Anal. Chem. 25, 350-356.

Edgar, B.A., Lehman, D.A., O'Farrell, P.H., 1994. Transcriptional regulation of string (cdc25): a link between developmental programming and the cell cycle. Development 120,3131-3143. 
Fagotto, F., 1990. Yolk degradation in tick eggs: I. Occurrence of a cathepsin L-like acid proteinase in yolk spheres. Arch. Insect Biochem. Physiol. 14, 217-235.

Forbes, Z., Ingham, P., 1993. Drosophila embryos. In: Stern, C.D., Holland, P.W.H. (Eds.), Essential Developmental Biology, A Practical Approach,, Oxford University Press, Oxford, pp. 3-20.

Gromysz-Kalkowska, K., Lechowski, L., 1992. Oxygen consumption in Trigonotylus coelestialium (Kirk) (Heteroptera) during its life cycle. Comp. Biochem. Physiol. 103A, 527-530.

Guerra, A.A., Cochran, D.J., 1970. Respiration during the life cycle of the face fly. J. Econ. Entomol. 63, 918-921.

Guerrero, F.D., Miller, R.J., Rousseau, M.E., Sunkara, S., Quackenbush, J., Lee, Y., Nene, V., 2005. A database of cDNAs expressed in Boophilus microplus, the tropical/southern cattle tick. Insect Biochem. Mol. Biol. 35, 585-595.

James, A.M., Oliver Jr., H., 1997. Purification and partial characterization of vitellin from the black-legged tick, Ixodes scapularis. Mol. Biol. 27, 639-649.

Kamel, Y.M., Fahmy, Y., Shalaby, Y., Ghazy, A.M., 1982. Biochemical studies of tick embryogenesis DNA, RNA, haemoprotein, guansine and guanine in developing eggs of Hyalomma dromedarii. Insect Biochem. 12, 15-23.

Logullo, C., Moraes, J., Dansa-Petretski, M., VazJr, I.S., Masuda, A., Sorgine, M.H.F., Braz, G.R., Masuda, H., Oliveira, P.L., 2002. Binding and storage of heme by vitellin from the cattle tick, Boophilus microplus. Insect Biochem. Mol. Biol. 32, 1805-1811.

Madhavan, M.M., 1975. Respiratory metabolism and energy sources during embryogenesis of the aquatic hemipteran, Sphoerodema molestum. Physiol. Zool. 3, 263-268.

Monnerat, A.T., Pelajo-Machado, M., Vale, B.S., Soares, M.J., Lima, J.B.P., Lenzi, H.L., Valle, D., 2002. Anopheles albitarsis embryogenesis: morphological identification of major events. Memórias do Instituto Oswaldo Cruz 97, 589-596.

Nusslein-Volhard, C., Roth, S., 1989. Axis determination in insect embryos. Ciba Found. Symp. 144, 37-55.

Parra, G., Ronnestad, I., Yúfera, M., 1999. Energy metabolism and larvae of the Senegal sole. J. Fish Biol. 55, 205-214.
Patel, N.H., 1994. Developmental evolution: insights from studies of insect segmentation. Science 266, 581-590.

Petitpren, M.F., Knight, A.W., 1979. Oxygen consumption of the dragonfly Anax junius. J. Insect Physiol. 16, 449-459.

Ponka, P., 1997. Tissue-specific regulation of iron metabolism and heme synthesis: distinct control mechanisms in erythroid cells. Blood 89, 1-25.

Rosell, R., Coons, L.B., 1991. Purification and partial characterization of vitelin from the eggs of the hard tick Dermacentor variabilis. Insect Biochem. 21, 871-885.

Sambrook, J., Fritsch, E.F., Maniatis, T., 1989. Molecular cloning, a laboratory manual, 2nd ed. Cold Spring Harbor Laboratory Press, New York, USA.

Sappington, T.W., Raikhel, A.S., 1998. Molecular characteristics of insect vitellogenins and vitellogenin receptors. Insect Biochem. Mol. Biol. 28, 177-300.

Sonenshine, D.E., 1991. Biology of Ticks, vol. 1. Oxford University Press, New York.

Speake, B.K., Murray, A.M., Noble, R.C., 1998. Transport and transformations of yolk lipids during development of the avian embryo. Prog. Lipid Res. 37, 1-32.

Takahashi, S.Y., Yamamoto, Y., Shionoya, Y., Kageyama, T., 1993. Cisteine proteinase from the eggs of the silkmoth, Bombyx mori: identification of a latent enzime and characterization of activation and proteolytic processing in vivo and in vitro. J. Biochem. 114, 267-272.

Thompson, M.B., Russel, K.J., 1999. Embryonic energetics in eggs of two species of Australian skink, Morethia boulengeri and Morethia adelaidensis. J. Herpetol. 33, 291-297.

Thompson, M.B., Stewart, R.J., 1997. Embryonic metabolism and growth in lizards of the genus Eumeces. Comp. Biochem. Physiol. 118A, 647-654.

Tonzetich, J., Ward, C.L., Denny, E., 1976. Effects of temperature and humidity on hydration and respiration in four strains of Drosophila. J. Insect Physiol. 22, 107-113.

Urich, K., 1990. Comparative Animal Biochemistry. Springer-Verlag, New York. 